\title{
11 The operational model of cinematic adaptation from Internet content in China
}

\author{
Xiaojuan Yan
}

\section{Box office performance of film adaptation from online content}

In 2014, Old Boys: The Way of the Dragon, a movie adapted from the microfilm Old Boys, took 25 million yuan at the box office on its first day of release, with 47 average viewers per show time, outperforming the Hollywood blockbuster Transformers 4: Age of Extinction which was released on the same day. In total, the Chinese film achieved a gross box office of 220 million yuan.

Another movie adapted from an Internet video program is One Hundred Thousand Bad Jokes, which achieved a total box office of 119 million yuan. Despite the fact that it barely surpassed the 100 million yuan threshold, the film marked a success in breaking the entrenched gross limit of 60 million yuan in the field of Chinese animation. Considering it cost only 10 million yuan in production and promotion, One Hundred Thousand Bad Jokes has achieved a considerably impressive return on investment.

In 2015, Pancake Man, a movie adapted from Sohu's drama Diors Man, achieved a total box office of 1.16 billion yuan. Apart from a high gross revenue, Pancake Man also received positive reviews with a score of 7 on Douban. The film's director Dong Chengpeng won "Best New Director" and "Best New Actor" awards at the 18th Shanghai International Film Festival.

Three years after the Internet drama Surprise was launched online, the show's producer UniMedia joined forces with Heyi Pictures to adapt it into a big-screen production of the same name, with Jiaoshou Yi Xiaoxing as director, Huang Jianxin as the executive producer, and Han Han as the art director. The film eventually achieved a gross box office of 320 million yuan.

A common feature shared by these films is that they are all adapted from microfilms or Internet dramas online that were highly popular for online viewing. Thus, these films eventually achieved extraordinary box office performances. Some experts estimate that big-screen films adapted from Internet-generated videos will bring a total revenue of more than 10 billion yuan in the next three to five years. 


\section{Reasons for the emergence of film adaptations from Internet content}

There are many reasons why films are adapted from Internet dramas. In this chapter, these reasons are analyzed by considering the various factors of the Internet dramas and the film industry.

\section{The film industry}

\section{Drama films adapted from the Internet cater to the audiences' tastes}

With the advent of the Internet era, networks have become the major or even the only channel from which the public receive information, conduct communication and seek entertainment. The Internet culture has also long become the core of popular culture. Statistics show that the user population of the Internet is mainly comprised of young people aged between 15 and 35, who happen to be the major film viewing group. The high overlap between film audiences and Internet users prompts an increasing number of filmmakers to seek inspiration from Internet content in order to capture the attention and interest of the mainstream population of film viewers. Therefore, popular online fictions and videos naturally become top choices for cinematic adaptation.

For instance, Diors Man upon which the film Pancake Man is based, received four billion clicks after being launched online, accumulating a massive pool of original users. These users will naturally also be converted into target audiences for its cinematic adaptation on the big screen.

\section{Adaptation effectively reduces film investment risks}

Given the high-risk nature of the film industry and the relatively unitary profit model of China's film industry, the majority of domestic films risk losing money. However, a well-established intellectual property (IP) of, for example, a literary work, play, Internet drama or comic, may have already secured a fixed group of fans with its narrative and fictional characters tested by the market. Thus, it will be easier for its cinematic adaption to succeed. This was indeed the case if we look at the emergence of a large number of successful works in the Chinese film market in 2015: Goodbye Mr. Loser, Go Away Mr. Tumor, and Jian Bing Man, etc.

Using data analysis and other tools, Internet dramas can accurately target their audience and thus establish effective marketing strategies. As mentioned earlier, the Internet drama Diors Man received 4 billion clicks online, helping to generate massive data for the confirmation of the success of its big-screen adaptation. In the meantime, the director Dong Chengpeng also engaged in active interactions with users on social media which also facilitated acquisition of user information. The marketing campaign of Pancake Man was successful as it is close to the real daily problems of the audiences. The offline marketing 
efforts also include events like "Da Peng Pancake Booth at Zhong Guancun" and "Da Peng Went to Lian Xiang Training School," as well as a roadshow in 35 cities. These marketing activities continuously accelerated the popularity of the film and successfully drew attention from audiences who were initially not fans of Diors Man, thus making the film an intensively debated topic among the public. With respect to online marketing, the marketing operator released different styles of posters based on the production cycle of the film to stimulate audience interest. A number of hot-spot events were also launched, for example, the Polish Beijing mini-game during Beijing's sandstorm season and the short animation Mom, You Are on My WeChat Moments on Mother's Day, which successfully helped the film obtain a favorable response from the audiences.

\section{Low trial and error cost}

At present, many content producers opt for developing Internet-generated content (i.e., content proprietarily produced by video sites, user-provided content on video sites) as intellectual properties and fan bases can easily be built online for such content at a relatively low cost. When a certain degree of maturity for Internet-generated content, models and details, and a certain level of fan recognition and fan numbers are reached, producers will be able to comprehensively upgrade their content. For instance, they may start to launch a broad range of offline activities to promote their content. When a story and its characters are generally accepted, an adaptation into a TV drama or film will become feasible.

A good example is the Internet drama Surprise, which was adapted into a film by its producers two and a half years after its initial release online. The producers have a very strict content selection process: they maintain a dozen production teams who propose a set of ideas for content creation every couple of months. The company's internal evaluation panel then decide whether a demo should be shot. If so, the demo will be evaluated to determine whether it can be further developed into a series or a microfilm, and on that basis, the question of whether investment should be made will be decided. Basically, it would take at least half a year for a project to be initially determined before entering the next stage of script development. If Internet dramas fail, this entails relatively lower costs, prompting repeated trial and error practice among producers.

\section{Internet dramas}

\section{The advent of the age of Internet-generated content}

With increasingly lowered technological thresholds, the rapid rise of mobile Internet and changes in users' content needs, the Internet-generated content has gained unprecedented prosperity with an unstoppable momentum. In the 
US, the popular culture represented by YouTube's video products has already become part of people's lives, presenting characteristics of commercialization and clusterization. In the list of the "top ten most influential teenagers in the U.S." provided by Variety in 2015, the most authoritative magazine in the entertainment industry, eight were YouTube celebrities or what are called "the Internet celebrities." In China, the video industry has also witnessed rapid development for more than a decade. The success of an array of Internetgenerated content, such as Old Boys, Diors Man, and Surprise, sufficiently indicates that a new era of Internet-generated content has arrived. Internetgenerated content such as online fictions and dramas has moved on from its earlier frippery and grassroots images and is increasingly becoming a part of mainstream culture. Internet-generated content has not only penetrated into traditional realms of $\mathrm{TV}$ and the big screens, but it has also been introduced to the entire world as effective cultural exports and received high popularity ratings in many mainstream evaluation platforms.

As noted above, the Internet drama Diors Man, the original online source for Pancake Man, has achieved cumulatively 4 billion views online since its launch, gaining great popularity among Internet users. The producers contributed to the theme selection, content selection, and style establishment, which can attract a huge number of fans on the Internet platform. According to statistical data, the present-day netizens are predominantly students, the self-employed and white-collar groups. In the context of social transition and unevenly allocated resources nowadays, they are plunged into a constant state of fatigue or uncertainty about their future. In the face of immense pressures arising from various aspects of society, such as problems of finance, family and individual development, they often feel a pressing need to escape from these daily pressures. Diors Man, in this regard, uses a self-mocking approach to endow characters with distinct personalities and meaning, giving rise to a variety of scenes where a down-to-earth "nobody" is placed in real-life scenarios where contradictions are eventually resolved through self-deprecating comedies. Such a mode of plot setting, as it turned out to be, successfully catered to the psychological needs of netizens, evoking an intense response and thus gaining a huge number of faithful viewers. In terms of narrative format, Diors Man adopts an approach similar to that of a short play, in combination with a non-linear narrative structure, interesting and diversified role play, cameo appearances of celebrities, making the film highly aligned with a fragmented viewing mode on new media platforms.

\section{Internet dramas need to find an effective profit model}

Presently, there are mainly three modes for playing online videos in China. The first mode is AVOD - advertising-based video on demand: users can watch a video clip for free after viewing an advertisement. The second mode is TVOD - transactional video on demand: for example, a user may spend 5 yuan to watch a new video and 2 yuan to view an old video. This mode has 
been implemented in China for more than five years but with little success. Globally speaking, this mode is only successful in a few particular markets such as South Korea, hence it can be considered as having little influence. The third mode is SVOD, which refers to subscription video on demand: this is a proven successful business model in the European, American, and Japanese markets. The viewing mode in China's Internet platforms is also gradually shifting from AVOD to SVOD. Works centering on content itself, such as films and Internet dramas, are also moving in the direction of SVOD. For instance, entire episodes of The Lost Tomb were launched online on the very first day of its release. Users can either view all episodes if they are willing to subscribe to it monthly or watch one episode per week otherwise.

Over a long period of time, China's Internet videos have mainly relied on advertising to sustain their operations. Since 2015, however, mainstream video sites have started to experiment with the paid viewership model for their dramas, but with limited profitability. Besides, it takes time to foster users' habit to pay for content. Therefore, adapting Internet dramas into big-screen films is the most effective way to make a profit.

\section{How to effectively operate Internet-generated content}

\section{Judgment of the adaptation value of Internet drama}

When discussing the phenomenon of IP-based adaptation, Zhou Tiedong says that four conditions must be met for a cinematic story: (1) it must be "shootable," that is, it is possible to transform it into visual and auditory languages; (2) it must be "financeable," that is, there must be investors who are willing to put money into it; (3) it must be "marketable," that is, the story has enough selling points to attract distributors and viewers to cover the cost; and (4) it must be "appreciable," that is, theater chains are willing to arrange screenings and audiences show their appreciation. These four standards also apply when judging whether an Internet drama should be adapted to the big screen.

Additionally, it is also crucial to judge whether an Internet drama has "communicability." The notion of communicability is simple: it refers to the ability to maximize the appeal to users' attention in order to pursue the maximum amount of stream frequency, which is also a goal sought by many producers today, as well as a starting point for producers considering adapting an online drama into a film project.

On the basis of communicability, a piece of online content should also have user "stickiness," that is, to facilitate users establishing a certain degree of loyalty and expectations of the content, encouraging them to continue to watch the second or third episode after the first episode, or even the big-screen film. Self-produced online content experienced three development stages, beginning with the "microfilm" stage. Microfilm was a concept popular in China around 2011, such as Old Boys. Subsequently, a new form of film called "micro-drama" emerged, with representative works such as Diors Man and 
Surprise. These are largely low-budget works mainly relying on a comedic style to win in the market. The concept of "self-made Internet drama" emerged in 2014, represented by works like Fleet of Time with the cost of a single episode exceeding 1 million yuan, but surpassing traditional TV dramas in terms of either production standards or cost.

As discussed earlier, self-made Internet content has gradually changed from modular content to serial content. At the microfilm stage, a sufficient level of user loyalty has not been established either toward the video platforms or toward the content itself; at the micro-drama stage, there might be a certain level of user loyalty toward platforms, but there was still a lack of ground to foster a sufficient degree of stickiness due to a loose connection between different episodes. It was not until the emergence of phenomenal self-made Internet dramas that user stickiness started to be reinforced as audiences began to feel an emotional attachment to dramatic characters, which contributes to a better condition for film adaptations from Internet dramas.

\section{The art of adaptation}

The process by which Internet dramas moved toward adapted big-screen works should be examined from three dimensions. The first dimension is the form. A good content product usually focuses on a certain form of medium expression, which can either be reality shows, interviews or talk shows. In fact, the audience often have an inherently intense curiosity and craving for some types of content. It is, therefore, necessary to establish the most easily acceptable form for users.

The second dimension is the story structure, encompassing characters, theme, story, genre and structure. When the "tonality" of the leading character in a story frequently changes, the content of such a story basically does not hold together, and it has little chance of success in the future. To make a successful adaptation of a story, first and foremost, one must facilitate the viewers recognizing and liking the characters in the story. A firm control of genres is equally important. After years of development, Hollywood has basically developed an effective set of classification method in terms of viewers' habit and preferences to arrange the first climax and the first low point at the right time in a film. The regularities of production should thus be observed in order to gain the emotional recognition of audiences. The last dimension is values, which includes aspirations for truth, goodness, beauty, emotion, courage and endeavor. A timeless content should be able to evoke an emotional resonance among the audience.

For instance, the following points were undertaken, when the Internet drama Pancake Man was adapted to the big screen. First, it abandoned the "short, adaptable and fast" meme-like drama mode. Instead of combining incoherent memes just for the sake of being funny, it has a complete, coherent storyline. Arguably, the film has its origin in an Internet drama but has eventually surpassed Internet dramas by all standards. Second, the film adopts 
a "drama within a drama" onion-layer structure, with a "superhero" inner narrative layer that reasonably connects the self-mocking performances of all the celebrities in the story. The outer layer, on the other hand, mainly functions as a depiction of the struggling and drifting life of Da Peng in Beijing. Such a structure effectively realized the combination of the original Internet drama and its film adaptation. According to Cheng Peng, the director, the preproduction period of Pancake Man took two years, and the filmmakers of each part had to follow the production procedures and standards of films strictly while adapting the Internet drama, which is why the film has gained broad recognition from the audience and the market.

\section{All-round development to build a "Hollywood model"}

Generally speaking, the "Hollywood model" means a cross-medium, crosschannel business operation model. The concept of a standalone film industry does not exist in Hollywood, rather, films are a sub-branch of a bigger entertainment industry. Major Hollywood media groups concurrently operate multiple forms of medium products, including films, books, TV shows, and games. Thus, content in Hollywood is developed in an all-round manner and one content product can create profits from a variety of medium channels. For example, when the Hollywood blockbuster Harry Potter, a very popular cinematic work among Chinese audiences was released, an array of products under the same name, including books, games, audiovisual products and licensed toys, schoolbags, and stationery products were also launched on the market. Leveraging the popularity of the film, these products generated substantial profits through diverse sales channels.

In contrast, the box office has been the main source of profits for the film industry in China and revenues coming from related business are negligible. This, naturally, is connected to China's political and economic institutions as well as the degree of development in various industries. Today, the emergence of the Internet has provided an opportunity for transitions to take place in the culture, entertainment and media industries. The Internet has improved the users' efficiency in obtaining video information, enabling them to acquire more diversified and higher quality content with lower costs in terms of space, time and money. Instead of imitating the development course of traditional industries which rely heavily on offline investments, the growth of the video industry should be completed through online derivations. For instance, videoadapted games, films and a combination with e-commerce have all emerged to strengthen the explosive growth of the entire industry.

China's game industry has been a rapidly growing industry that entails light investments. In 2015, the total market value of the game industry exceeded 140 billion yuan. However, the connection between the game industry and the film and video industries had been quite loose in the past. Today, with the advent of the Internet, such a connection has becoming increasingly close. For instance, the streaming platform of the TV drama The Journey of 


\section{Xiaojuan Yan}

Flowers, which was released in 2015, engaged in various forms of cooperation with developers and operators. However, the total royalty and online advertising fees generated by the TV drama were significantly less than the revenues from the game of the same name. Therefore, games are a fairly good kind of derivative for Internet-generated content. This represents a light investment that combines content, especially in a form that is popular among young consumers, with entertainment in order to generate more value.

Presently, the connection between videos and products is still in its explorative stage, compared with TV shopping, which is now quite mature. Nevertheless, this connection is the correct way to follow because such a combination has greater potential for growth in future and may give rise to more detailed business patterns.

Compared with the predominant offline business model developed by Hollywood over a century, a similar online model can be established thanks to the Internet. Undoubtedly, this will occur, not through simple imitations, but through innovations by taking the characteristics of the Internet into account. As such, it can be said that films adapted from Internet drama represent an effective way to learn from the Hollywood business model with a view to creating a "mega-entertainment industry" of our own in China. 